\title{
Community-based conservation and social change amongst South Indian honey-hunters: an anthropological perspective
}

\author{
Paul Nicholas Anderson
}

\begin{abstract}
This article reconsiders the use of financial incentives for securing the participation of 'local' people on conservation programmes by raising several less discussed social consequences which such incentives may entail. To this end, it outlines the involvement of a South Indian honey-hunting 'tribe' with an ecodevelopment programme and the market economy, noting how commercializing 'traditional' livelihoods may increase the general 'standard of living' but undermine the social
\end{abstract}

'fabric' of the community and aid in the rationalization of custom. It concludes by suggesting that social development should precede economic development for communities in transition between subsistence and commodity-orientated economic practices.

Keywords Commodification, community-based conservation, ecodevelopment, honey-hunting, India, social change.

\section{Introduction}

Recent years have witnessed an increasing trend in 'developing' countries toward community participation in conservation projects with income generation as the prime incentive (Wells \& Brandon, 1992; International Institute for Environment and Development, 1994; Milner-Gulland \& Mace, 1998). Whereas many have voiced reservations about converting vernacular societies (typically 'indigenous', subsistence and/or precapitalist) in particular to mainstream economic practice (e.g. Taussig, 1978; Colchester, 1994), relatively few have addressed this concern within the context of conservation (Milner-Gulland \& Mace, 1998). This brief article follows this concern, discussing the recent involvement of a South Indian tribe with the market economy and an ecodevelopment project and both highlights several problematic features of the relationship and suggests several means by which these may be rectified.

\section{Honey-hunting}

The collection of rock honey (of Apis dorsata) from the towering cliffs of the Nilgiri Hills of South India holds special significance for the indigenous Alu and Jenu Kurumba tribes (sometimes known as Kurubas). Considered for centuries a highly valued good, rock honey or Barajenu has been collected and exchanged by the forest-dwelling, hunter-gatherer Kurumba with

P. N. Anderson Institute of Ecology and Resource Management, University of Edinburgh, Kings' Buildings, Edinburgh EH9 3JU, Scotland. Mailing address: Department of Philosophy, University of Warwick, Coventry CV4 7AL, UK. E-mail: pnanderson@eudoramail.com neighbouring tribes for items the Kurumba could not procure themselves. The honey-hunting process itself is, even today, embedded in a system of sharing, rituals, prayers, offerings and honey-songs that serve to reaffirm the Kurumba's kinship with the bees and to engender respect for the cliff-dwelling deities. As far as records reveal, honey-hunting has most often been undertaken by the conjugal pair, a social unit central to the reproduction of Kurumba society (Bird-David, 1989; Demmer, 1997). For these reasons (not to mention the substantial danger on the cliffs that bonds the collection group together), honey-hunting has been thought of as a 'habitus' (Demmer, 1997), a practice that mediates symbolic form (ritual, deities), social action (the gathering process) and social structure (conjugal pair) in a manner habitually constitutive of Kurumba society.

This custom-laden, socially significant practice has also aroused the interest of conservationists. If, for example, a cliff-deity refuses the Kurumba's offering (interpreted in various ritualistic ways), it signals the deity's displeasure with the venture and the cliff face will be left alone for the rest of the season. Moreover, cliffs which are the scene of a climber's death become strictly taboo. As a result of both observances, in some areas up to 80 per cent of $A$. dorsata hives are left untouched. It is an unintended consequence perhaps of such customs that the $A$. dorsata population in the Nilgiris is said never to have been threatened with over-exploitation.

\section{Kurumba and modernity}

Events of the 20th century, however, have conspired to alter Kurumba honey-hunting. By the time of 
Independence in 1947, most tribal peoples in India had been displaced from forest areas and their livelihoods subsequently marginalized. As Kurumba people were no longer able to subsist predominantly on forest produce or depend on fast eroding inter-tribal exchange systems (Noble, 1968; von Fürer-Haimendorf, 1985), many have proceeded to sell minor forest produce where possible through state authorized co-operatives supplemented by available wage-labour (usually on tea plantations).

The transition has been far from smooth. Commercializing traditional livelihoods is often a double-edged sword and the Kurumba are no exception. Greater exposure to the market economy and mainstream Tamil culture has no doubt brought the tribals material benefits, some improvements in health and access to education, but it has by no means always impacted beneficially on their culture. The younger Kurumba generation, in particular, appear less interested in collecting honey and other forest produce than their forebears, preferring instead the offerings of consumer society secured by stable and more lucrative mainstream jobs. Those who actively continue honey-hunting have in some cases witnessed a simplification of elaborate prayer ceremonies and a shortening or even dropping of the honey-song (Keystone, 1994; Anderson, 2000), changes thought to be a consequence of rationalizing and thereby 'disenchanting' the collection process $^{1}$. Nowadays, even conjugal pairs rarely form the basis of collection groups (Anderson, 2000). The result of this cultural 'erosion' is largely predictable. If the observance of rituals, honey-songs and the like is a defining feature of the time-honoured honey-collecting habits of Kurumba society, then it follows that the nonobservance and displacement of such customs undermines the integrity of Kurumba society (see below).

And what of those customs which serve to regulate the exploitation of honey (observing taboos, permissionseeking of cliff deities, etc.)? While most Kurumba still strictly observe taboos (their significance resides not only in symbolic meaning but also in 'magic' and are hence greatly feared if transgressed), it is interesting to note that the (more) educated young are now seeking proof for cultural taboos, whereas previously the authority of custom resided in tradition, which itself remained unquestioned. As this questioning continues, it is feared that customs which ally with conservation

\footnotetext{
1'Rationalization' here refers to the experience wherein the 'economic function' of an activity becomes recognized as distinguishable from its 'social function' by the agents of that activity (Bourdieu, 1979).

A rationalized practice (e.g. some honey hunting) typically accords primacy to its instrumental evaluation (usually monetary) at the expense of those ways and means (discussed above) by which it was valued when embedded within, and inextricable from, its social context.
}

aims may be inadvertently abandoned by the younger generation.

\section{What can be done?}

Like several conservation organizations in the Nilgiris, Keystone, an ecodevelopment non-governmental organization, has recently taken on the challenge of arresting cultural decline by integrating it within their objectives of biodiversity conservation and economic betterment. Their hope, in this respect, is for the Kurumba's (and other tribals') continuation of existing honey-hunting practices and an expansion into general apiculture (with the native bee, Apis cerana). To this end, Keystone supply beeboxes, provide technical assistance, purchase honey and wax at premium prices and train locals in the processing and marketing of honey-products with the intent of enabling this enterprise to be run one day by the tribals themselves. If they have no choice but to participate in the market, Keystone maintains, let it be in ways of cultural and personal importance to them. Furthermore, enhancing income generation from these often poorly paid activities is likely to preserve tribals' interest in the bees which, in turn, supports a Keystone species crucial to the maintenance and regeneration of the forest area.

Although it is yet too early to gauge the conservation benefits of Keystone's intervention (the 'biodiversity programme' commenced in 1994-95 in most involved villages), it is worth mentioning one or two potential social problems that, with care, may be minimized or counteracted.

Attempting to preserve or promote traditional practices and customs on the basis of their value to conservation and newfound role of enhancing economic returns may actually prove to be a Trojan horse of change. When 'traditional' knowledge and practice receive their justification primarily in this manner, tradition becomes justified 'only in light of knowledge which is not itself authenticated by tradition' (Giddens, 1990), the very opposite of tradition. As a result, Giddens remarks, justified tradition is tradition in sham clothing' (Giddens, 1990). This predicament, beyond the scope of the present article, is discussed in Anderson (2000).

A further problem with the promotion of income generation is its tendency to exacerbate individualistic behaviour, which may lead to community fragmentation (cf. Taylor, 1991). Market freedom may come to mean freedom from traditional duties and obligations including, as has been observed, from community law (Taussig, 1978; von Fürer-Haimendorf, 1985). To help ameliorate these affects on communities in transition, social development should precede economic develop- 
ment. This could be, for instance, in the form of a village, women's and youth Sangham or 'forum' that may facilitate new forms of solidarity in times of change. Social development of this kind would be especially pertinent to communities subject to unscrupulous middle-men and money-lenders whose snares of deception and debt-creation may thrive on a community's increasing prosperity. Of course, Sangham building by no means guarantees that a community will retain (or want to retain) its integrity, but it should at least provide a platform upon which the direction of community development can be influenced by voices and values other than those solely economic.

Above all perhaps, it is necessary to clarify from the outset what counts as success. It is (comparatively) easy to measure the success of biodiversity conservation or economic well-being, but cultural integrity? Such a question depends upon one's concept of culture and, as a consequence, it would appear vital to be clear about this if community-based biodiversity conservation and economic improvement in turn are to succeed.

\section{Acknowledgements}

I am indebted to S. Nath, P. Roy, R. Leo and M. John of Keystone Foundation, to Rev. P. Mulley (Kotagiri, Tamil Nadu), Mavanhall Youth Welfare Association (Masinagudi, Tamil Nadu), to Ashoka Trust for Research in Ecology and the Environment (Bangalore) and to my guides A. Ramakrishnan and N. Jalendran for their kind and invaluable assistance during fieldwork. I am also very grateful to Justin Kenrick and Neil Thin of Edinburgh University for their thorough and welcome guidance.

\section{References}

Anderson, P.N. (2000) Commodification, Conservation and Community: an Analysis and a Case Study in South India. Edinburgh Papers in South Asian Studies No. 14. Centre for South Asian Studies, University of Edinburgh, Scotland.
Bird-David, N. (1989) An introduction to the Naikens: the people and the ethnographic myth. In Blue Mountains: the Ethnography and Biogeography of a South Indian Region (ed. P. Hockings), pp. 249-280. Oxford University Press, Delhi.

Bourdieu, P. (1979) Algeria 1960: the Disenchantment of the World, (translator R. Nice) Cambridge University Press. Cambridge.

Colchester, M. (1994) Salvaging Nature: Indigenous Peoples, Protected Areas and Biodiversity Conservation. United Nations Research Institute for Social Development (UNRISD) discussion paper, Geneva.

Demmer, U. (1997) Voices in the forest: the field of gathering among the Jenu Kurumba. In Blue Mountains Revisited: the Ethnography and Biogeography of a South Indian Region (ed. P. Hockings), pp. 164-191. Oxford University Press, Delhi.

Giddens, A. (1990) The Consequences of Modernity. Polity Press. London.

von Fürer-Haimendorf, C. (1985) Tribes of India: The Struggle for Survival. Oxford University Press, Delhi.

International Institute for Environment and Development (1994) Whose Eden? An Overview of Community Approaches to Wildlife Management. International Institute for Environment and Development, London.

Keystone (1994) Honey Hunters and Beekeepers of Tamil Nadu Keystone Foundation, Pondicherry, India.

Milner-Gulland, E.J. \& Mace, R. (1998) Conservation of Biological Resources. Blackwell Science Ltd., Oxford.

Noble, W. (1968) Cultural Contrasts and Similarities among Five Ethnic Groups in the Nilgiri District, Madras State, India 18001963. PhD Thesis. University of Georgia, USA.

Taussig, M. (1978) The Devil and Commodity Fetishism in South America. University of North Carolina Press, Chapel Hill.

Taylor, C. (1991) The Ethics of Authenticity. Harvard University Press, London.

Wells, M. \& Brandon, K. (1992) People and Parks: Linking Protected Area Management with Local Communities. World Bank/WWF/USAID, Washington, DC.

\section{Biographical sketch}

Having studied philosophy, ecology and anthropology and taught philosophy and geography, Paul Anderson currently consults on contemporary socio-environmental concerns with Lusis (lusis@gmx.net). 